Brain, Behavior and Evolution
Brain Behav Evol 2019;93:182-195

DOI: $10.1159 / 000501161$
Received: July 10, 2018

Returned for revision: August 5, 2018 Accepted after 3rd revision: May 22, 2019

Published online: August 22, 2019

\title{
Rethinking the Effects of Body Size on the Study of Brain Size Evolution
}

\author{
Enrique Font ${ }^{\mathrm{a}}$ Roberto García-Roa ${ }^{\mathrm{a}}$ Daniel Pincheira-Donoso ${ }^{\mathrm{b}} \quad \mathrm{Pau}$ Carazo $^{\mathrm{a}}$ \\ ${ }^{a}$ Ethology Lab, Instituto Cavanilles de Biodiversidad y Biología Evolutiva, University of Valencia, Valencia, Spain; \\ ${ }^{b}$ MacroBiodiversity Lab, School of Biological Sciences, Queen's University Belfast, Belfast, UK
}

\section{Keywords}

Bird · Brain-body scaling · Brain evolution · Brain size .

Comparative cognition $\cdot$ Reptile

\begin{abstract}
Body size correlates with most structural and functional components of an organism's phenotype - brain size being a prime example of allometric scaling with animal size. Therefore, comparative studies of brain evolution in vertebrates rely on controlling for the scaling effects of body size variation on brain size variation by calculating brain weight/ body weight ratios. Differences in the brain size-body size relationship between taxa are usually interpreted as differences in selection acting on the brain or its components, while selection pressures acting on body size, which are among the most prevalent in nature, are rarely acknowledged, leading to conflicting and confusing conclusions. We address these problems by comparing brain-body relationships from across $>1,000$ species of birds and non-avian reptiles. Relative brain size in birds is often assumed to be 10 times larger than in reptiles of similar body size. We examine how differences in the specific gravity of body tissues and in body design (e.g., presence/absence of a tail or a dense shell) between these two groups can affect estimates of relative
\end{abstract}

brain size. Using phylogenetic comparative analyses, we show that the gap in relative brain size between birds and reptiles has been grossly exaggerated. Our results highlight the need to take into account differences between taxa arising from selection pressures affecting body size and design, and call into question the widespread misconception that reptile brains are small and incapable of supporting sophisticated behavior and cognition.

(c) 2019 S. Karger AG, Basel

\section{Introduction}

Our understanding of vertebrate brain evolution rests largely on comparative analyses quantifying interspecific differences in brain size and structure [Striedter, 2005]. Given that brain size scales predictably with body size, reporting the size of the whole brain or of its individual components as brain/body ratios and presenting comparative data graphically on bivariate brain size-body size plots are a widespread practice [Schmidt-Nielsen 1984]. The relationship between brain and body size is allometric rather than isometric, such that on a log-log plot of brain size on body size, the data points for a given taxonomic group fall around a regression line with a slope of

\section{KARGER}

(c) 2019 S. Karger AG, Basel

E-Mail karger@karger.com

www.karger.com/bbe 
less than one [Harvey and Pagel, 1988]. There has been much debate about the biological significance of the slope of the regression line and of the magnitude of the residuals from this relationship across species [Deacon, 1990; Montgomery et al., 2016]. The latter have often been interpreted as reflecting cognitive ability or adaptations to particular ecological conditions [e.g. Emery et al., 2007; Shettleworth, 2010; Menzel and Fischer, 2011]. In general, however, models of brain evolution have focused on interpreting relative brain size based on selection pressures acting on the numerator of the brain/body ratio, while the effects that selection exerts indirectly on brain size through its effects on body size remain largely neglected. Here, we explore how not taking into account selection pressures on body size can distort estimates of relative brain size, giving rise to long-standing and heavily entrenched misconceptions regarding differences between taxa [see Smaers et al., 2012]. We use Reptilia as a case study, a highly diverse group that contains two major vertebrate radiations - birds and non-avian reptiles whose brain sizes and cognitive achievements are often subject to comparison.

Birds have brains that are as large as or even larger than those of mammals of similar body size. Non-avian reptiles and most ectothermic vertebrates, on the other hand, have brains that are smaller, relative to their body size, than those of birds and mammals. But, how much larger are bird brains compared to reptilian brains? Published estimates range widely, but most authors state that the average difference is 10 -fold, i.e. a bird or a mammal have a brain 10 times larger (heavier) than a reptile of similar body size [e.g. Martin, 1981; Hurlburt, 1996; van Dongen, 1998; Northcutt, 2011; Hurlburt et al., 2013; Dicke and Roth, 2016; Güntürkün et al., 2017; Shimizu et al., 2017]. Such large difference is puzzling considering the phylogenetic relatedness between birds and reptiles and the similarities in brain organization between these two groups. For example, in stark contrast to mammals, the largest portion of the pallium in both birds and reptiles is subcortical, located ventral to the lateral ventricles, and gives rise to a structure known as the dorsal ventricular ridge (DVR, also called the nidopallium and mesopallium in birds). The DVR receives ascending visual, auditory, and somatosensory thalamic projections, and is considered by many to be functionally convergent with the mammalian neocortex [Butler and Hodos, 2005; Jarvis, 2009; Güntürkün et al., 2017; Yamashita and Nomura, 2017; Tosches et al., 2018]. As reptile brains are similar in relative size to those of terrestrial frogs, toads, and teleost fish [Striedter, 2005; van Dongen, 1998], the large size dif- ference between birds and reptiles has been interpreted as evidence that, during the reptile-bird transition, bird brains massively increased their size while those of nonavian reptiles barely budged.

The 10-fold figure describing the average brain size difference between birds and reptiles can be traced back to the work of Harry Jerison, who conducted the first serious attempt to compare brain size data across different vertebrate lineages. Jerison [1973] famously plotted brain and body weight data on a log-log scale and drew minimum convex polygons enclosing the data points for different taxonomic groups (Fig. 1). The polygons show an orderly relationship, those of birds and mammals laying above the polygons of other vertebrate radiations. Although much criticized, Jerison's polygon plots are intuitively pleasing because they suggest a progressive increase in relative brain size during vertebrate evolution that roughly matches the assumed intelligence rankings informally assigned to the various vertebrate groups. Jerison's polygons have been reproduced in countless publications, often used to justify the presumed cognitive superiority of birds and mammals: the polygons for birds and mammals show almost complete overlap, yet a prominent gap separates the bird-mammal polygon from the polygon representing the remaining vertebrates (Fig. 1). Jerison [1973] fitted by eye lines with a $2 / 3$ slope to the different polygons and estimated the average difference in brain size between "higher" (mammals and birds) and "lower" (reptiles, amphibians, and fish) vertebrates to be one order of magnitude $(10 \times)$.

The most commonly used metric in comparative studies of brain size is mass: brain mass and body mass. The problem with a comparison based on mass should be obvious but has rarely been acknowledged: in a comparison between a bird and a reptile of the same body mass, the bird tends to be considerably larger than the reptile. This is basically due to several peculiarities of bird anatomy related to flight. The evolution of avian flight was attended by several weight-saving adaptations that have been key to reduce its metabolic costs [Gill, 2007]. Birds, for example, have an extensive system of air sacs extending into the viscera, muscles, and under the skin. Air sacs also opportunistically invade and hollow out the postcranial skeleton, which has the effect of reducing skeletal mass [Wedel, 2005]. As a result, most birds have a lower body density than mammals or reptiles [Hazlehurst and Rayner, 1992]. As brain density is the same across all vertebrates [e.g., Iwaniuk and Nelson, 2002; Domínguez Alonso et al., 2004], a comparison of relative brain size based on mass is necessarily biased and will tend to mag- 
Fig. 1. Polygon plots and allometric lines depicting relative brain size across vertebrates. a From Jerison [1973]. b From Witmer et al. [2003]. The upper minimum convex polygon in a contains data for mammals and birds, while the lower polygon encloses the data points for reptiles, amphibians, and bony fish (Osteichthyes). Regression lines in a are visually fitted lines with slopes of $2 / 3$, whereas those in $\mathbf{b}$ were calculated using non-phylogenetic (i.e., uncorrected) reduced major axis regression. Note the 10 -fold average difference in relative brain size between Jerison's "higher" and "lower" vertebrates (0.07/0.007). The minimum convex polygons in $\mathbf{b}$ correspond to the two radiations of extant Reptilia: birds and non-avian reptiles [data from Hurlburt, 1996]. Rhamphorhynchus and Anhanguera are extinct pterosaurs (brain sizes calculated from virtual endocasts obtained using X-ray computed tomography). $\mathrm{E}$ and $\mathrm{P}$ in a correspond to brain and body mass, respectively. In $\mathbf{b}$ brain mass was measured in milligrams, whereas body mass was measured in grams.
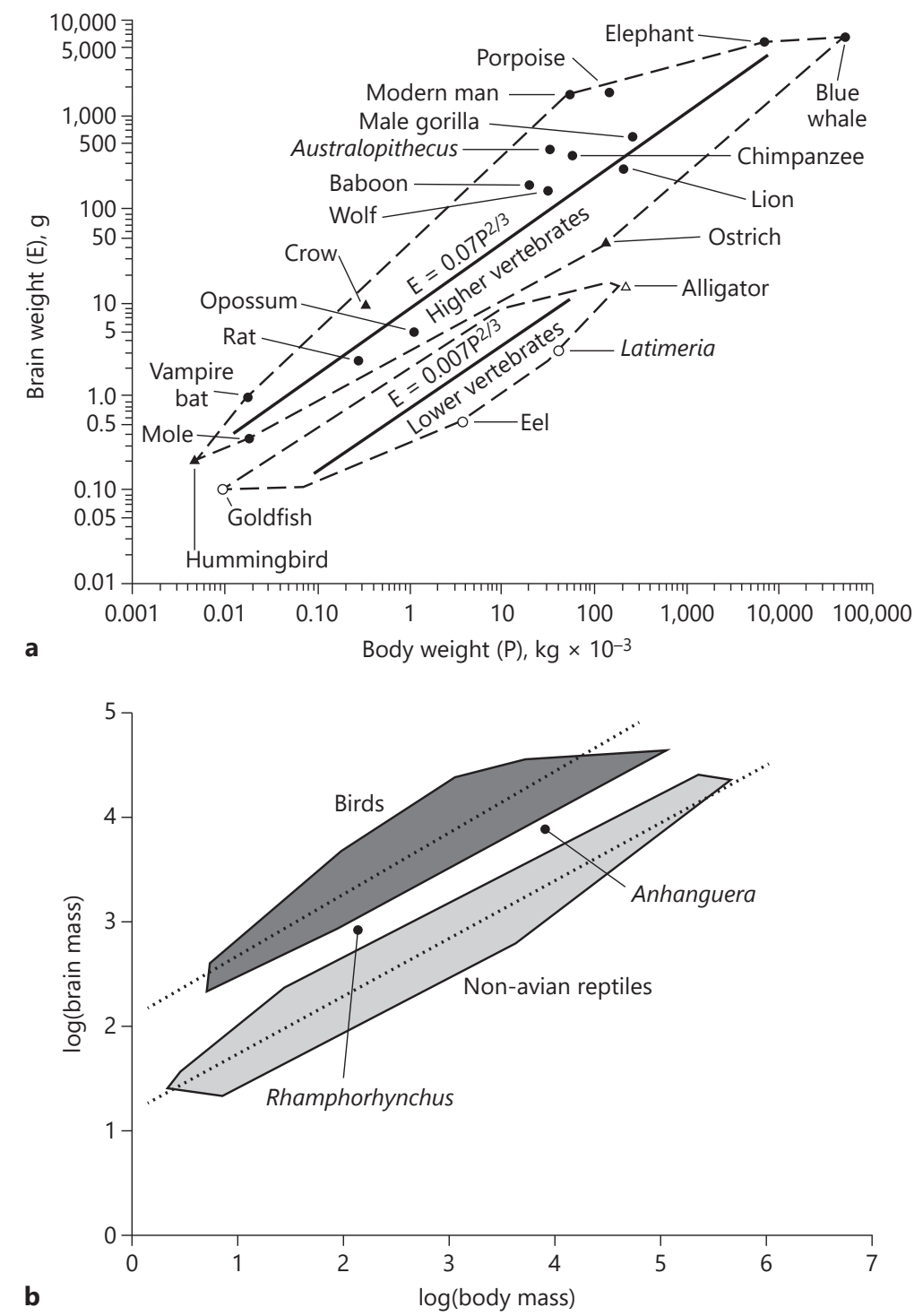

nify the differences between birds and reptiles. The same argument applies to comparisons between bird taxa subject to divergent selection pressures affecting body mass or body size. For example, aerial predators such as falcons (Falconidae) have a lower body density than ground-eating Galliformes such as turkey, grouse, pheasant, and chicken [Hazlehurst, 1991; Hamershock et al., 1993]. Thus, a falcon is lighter than a gallinaceous bird of similar body size (volume), which introduces bias in calculations of any variable that is expressed as a fraction of body mass.

Other potentially confounding factors have to do with differences in the body design (bauplan) of different taxa, such as birds versus non-avian reptiles. Most lizards and crocodiles have a tail that accounts for a large percentage of their total body mass [e.g. Jagnandan et al., 2014]. The "tail" of a bird is mostly feathers and, therefore, very light in comparison. Interestingly, many lizards are capable of shedding the tail as an antipredator adaptation and therefore spend part of their lives with missing or incomplete tails. As another example, many turtles are encased in a dense and heavy carapace, and as a result tend to be heavier than other reptiles of similar body size. This suggests that the large gap between the bird and reptile polygons could, to some extent, simply reflect the fact that the bodies of birds are lighter than expected given their brain 
mass. Using a dataset of brain and body size for 175 species of extant reptiles and 934 species of living birds, we examine variation in brain size in birds and reptiles and inquire about the effect of correcting for differences in body density and bauplan both across and within these two taxa.

\section{Materials and Methods}

We collated data on brain and body mass from published literature sources [Crile and Quiring, 1940; Platel, 1974, 1975, 1979; Black, 1983; Amiel et al., 2011]. Only adult individuals of either sex were considered. Literature sources that did not specify the protocol used for brain extraction, preparation (e.g., removing the meninges), and weighing were not considered. We also excluded reports of brain mass obtained after removal of a part of the brain (e.g., olfactory bulbs, brainstem), or that calculated brain mass/ volume based on stereological reconstructions of brain slices. For the snakes Hierophis viridiflavus and Natrix natrix we calculated a weighted average of the data provided in Crile and Quiring [1940] and Platel [1975]. In all remaining cases in which brain and body mass data for the same species were available from different sources, we used the dataset with the largest sample size. Data from the literature were supplemented with unpublished data on brain and body mass obtained from the authors ( 9 species; see acknowledgements), and with our own data for Podarcis liolepis.

Platel's dataset comprises data on brain and body mass for approximately 60 species of reptiles and has been used extensively in previous analyses [e.g., Hurlburt, 1996; van Dongen, 1998], but contains a number of shortcomings that limit its usefulness. Sample sizes are very uneven, ranging from 1 individual (e.g., Agama agama) to 88 (Lacerta viridis). For species with small sample sizes, Platel calculated brain mass as the average of the brain masses of all the individuals included in the sample. However, for larger samples ( $>30$ individuals), the brain mass values reported by Platel are estimates based on measurements taken from a single individual considered "representative" of its species (the predicted brain mass corresponding to an "average adult" of the species) [Platel, 1974]. Nonetheless, as raw brain and body mass data are provided in the original papers, in most cases we were able to substitute average values for Platel's estimates. Likewise, some of the brain mass values for Australian lizards taken from Black [1983; Tables 3-7] were recalculated using all the available adult specimens listed in Appendix I of the thesis and excluding four species of Varanus for which brain mass was estimated rather than measured.

The density (specific gravity) of fresh brain tissue is close to one in mammals, birds, and reptiles [Jerison, 1973; Hurlburt, 1996]. To calculate the brain volume of the reptile and bird species in our sample we used a common specific gravity of $1.036 \mathrm{~g} \mathrm{~mL}^{-1}$ [Padian and Chiappe, 1998; Iwaniuk and Nelson, 2002; Domínguez Alonso et al., 2004]. Body volumes for reptiles were calculated from body mass data using a conservative overall tissue specific gravity of $1.025 \mathrm{~g}$ $\mathrm{mL}^{-1}$, which is the average of specific gravity values for eight species available in the literature [Colbert, 1962; Jackson, 1969; Hurlburt, 1999; Hochscheid et al., 2003; Peterson and Gomez, 2008].

Brain and body mass data for 934 species of birds were likewise retrieved from published accounts [Armstrong and Bergeron,
1985; Mlikovsky, 1989a-d; Rehkämper et al., 1991; Iwaniuk and Nelson, 2001, 2002; Garamszegi et al., 2002; Iwaniuk and Arnold, 2004; Day et al., 2005; Payne, 2005; Cnotka et al., 2008; Corfield et al., 2008; Galván and Møller, 2011]. For several species for which we collected more than one data point we used averages. Bird body masses were transformed into volumes using available data for bird body density (online suppl. Table ESM1; for all online suppl. material, see www.karger.com/doi/10.1159/000501161). Where body density estimates were available for a given order, the same density value was applied to all species belonging to that order. For the remaining species we used a class-wide density of $0.718 \mathrm{~g}$ $\mathrm{mL}^{-1}$, which is the unweighted average of all the available body density values for birds.

Although previous studies comparing relative brain size in birds and reptiles have not consistently employed phylogenetic control, we performed regression analyses to estimate the magnitude of the allometric scaling (i.e., the slope and intercept) using phylogenetic generalized least squares (PGLS) to account for the non-independence of species data points due to their shared evolutionary history [Symonds and Blomberg, 2014]. Bivariate PGLS regressions were performed with the R [R Core Team, 2014] package "caper" [Orme et al., 2012]. Slopes and intercepts were calculated separately for mass, volume, and volume minus tail data (see below). All mass and volume data were $\log _{10}$ transformed before analyses.

Phylogenetic trees for 584 species of birds and 151 species of reptiles were constructed based on the time-calibrated molecular supertrees provided by Burleigh et al. [2015] and Tonini et al. [2016]. As turtles and crocodiles were absent in the Tonini et al. [2016] supertree, none were included in the phylogenetic tree for reptiles. Based on the separate trees for birds and reptiles, we created a supertree that contains both lineages. We used the approach developed by Roquet et al. [2014], which joins the source trees using the R package "ape" [Paradis et al., 2004]. We first obtained the ages since divergence between reptiles and birds from the estimates provided by the TimeTree (www.timetree.org) phylogenetic database [Hedges et al., 2006], which yielded an estimate of divergence of 280 mya. Once we set the divergence, the analysis calculates the ages of episodes since divergence for the rest of the nodes to assemble the supertree. This phylogenetic supertree was then employed to test for significant differences in intercepts and slopes of bird and reptile regression lines (see below).

Jerison and others estimated the difference in braininess between birds and reptiles to be 10 -fold by looking at the separation between the intercepts of the corresponding regression lines. However, before comparing intercepts, it has to be established that the slopes of the regression lines being compared are not significantly different [Sokal and Rohlf, 2012]. Therefore, we tested for the equality of intercepts and slopes between birds and reptiles using phylogenetic ANCOVA [Smaers and Rohlf, 2016] and the phylogenetic supertree described above. We compared slopes between brain-body relationships while holding the intercept constant, and then performed tests comparing the intercepts holding the slope constant. To further assess differences between slopes, we applied a subsequent test based on a model that holds slopes constant (and where intercepts vary), against a model in which both intercepts and slopes vary. These analyses were performed using phylogenetic tests implemented in the R packages "caper" [Orme et al., 2012], "phytools" [Revell, 2012], "nlme" [Pinheiro et al., 2018], "geiger" [Harmon et al., 2008], and "evomap" [Smaers and Mon- 
Fig. 2. Brain-body scaling in a sample of 175 species of living reptiles using: brain and body mass (a), and brain and body volume (b). Data for brains and bodies are in different units to avoid negative intercepts. The regression lines are from phylogenetically corrected analyses using PGLS. The data for turtles have been corrected in $\mathbf{b}$ to account for the dense shell, except in the case of the softshell turtle (A. ferox), which is by far the turtle with the highest relative brain mass in our dataset (red arrow in a). Note how turtles seem to have relatively small brains for their body size in a (i.e., most points fall below the regression line), but not in $\mathbf{b}$. The phylogenetically corrected regression lines in $\mathbf{a}$ and $\mathbf{b}$ are identical because our phylogenetic tree for reptiles did not include any turtles.

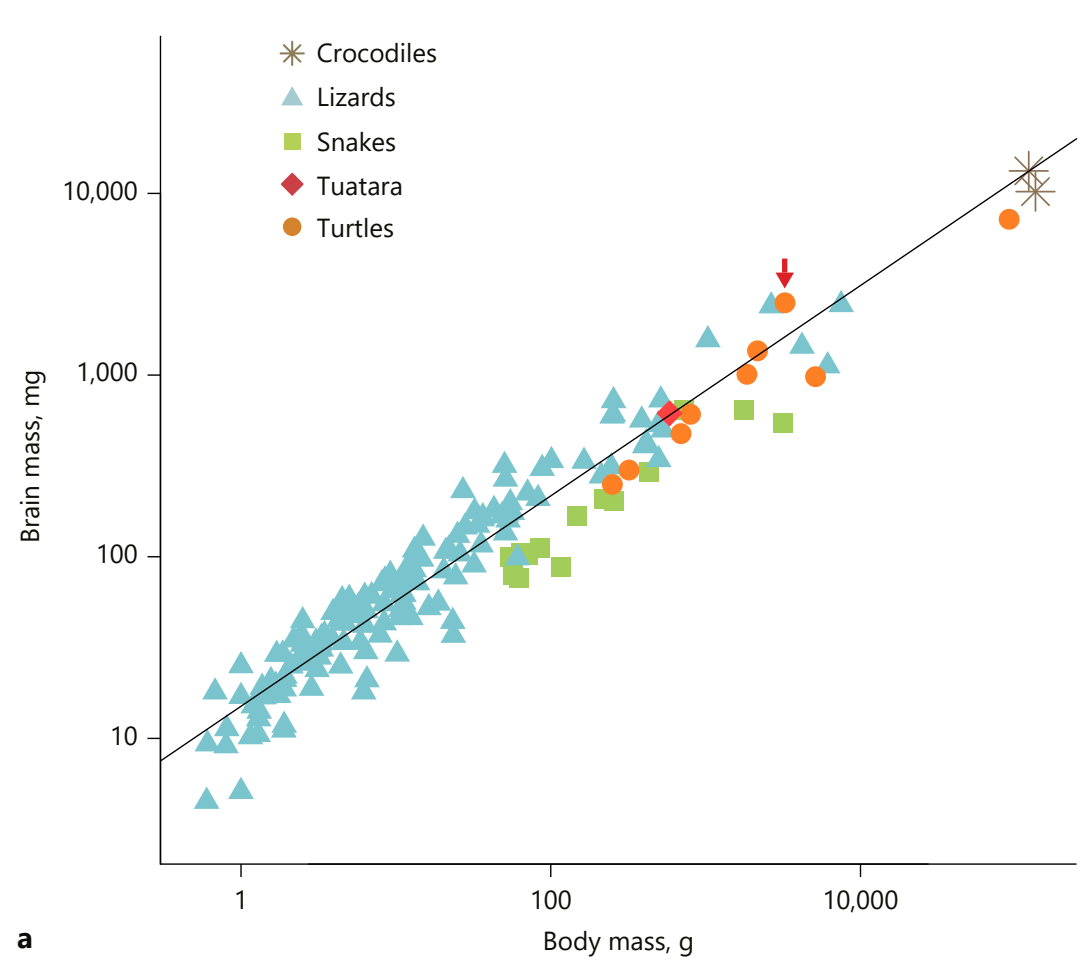

a

Body mass, $\mathrm{g}$

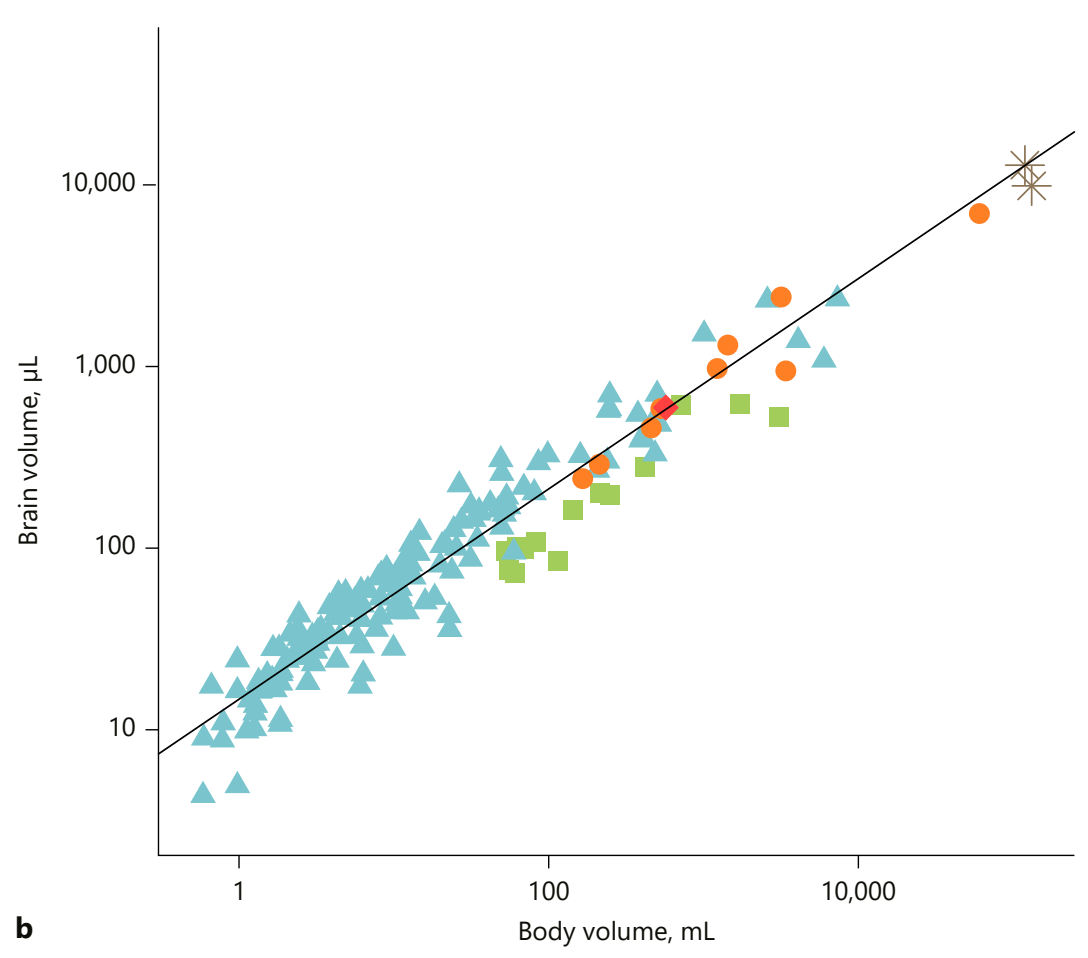


Table 1. Regression parameters for $\log _{10}-\log _{10}$ analyses of the relationship between brain and body size in birds and non-avian reptiles using phylogenetically corrected PGLS regression

\begin{tabular}{llllllll}
\hline Taxon & Regression & $n$ & Slope & Intercept & $R^{2}$ & $\lambda$ & Birds $>$ reptiles \\
\hline Birds & BrM vs BdM & 584 & 0.579 & 1.987 & 0.87 & 0.92 & 6.5 \\
Reptiles & BrM vs BdM & 151 & 0.579 & 1.177 & 0.91 & 0.89 & \\
\hline Birds & BrV vs BdV & 584 & 0.577 & 1.900 & 0.86 & 0.92 & 5.4 \\
Reptiles & BrV vs BdV & 151 & 0.579 & 1.168 & 0.91 & 0.89 & \\
\hline Birds* & BrV vs BdV & 584 & 0.577 & 1.900 & 0.86 & 0.92 & 4.8 \\
Reptiles & BrV vs Bd-tailV & 151 & 0.574 & 1.223 & 0.91 & 0.90 & \\
\hline
\end{tabular}

The last column provides an estimate, based on the separation of the corresponding intercepts, of the size difference between bird and reptile brains for each pairwise comparison (slopes are not significantly different; see text). The row for birds marked with an asterisk is duplicated to allow for a comparison between birds and reptiles after accounting for the volume of the tail in reptiles. BrM, brain mass; BdM, body mass; BrV, brain volume; $\mathrm{BdV}$, body volume; Bd-tailV, body volume after discounting the fraction corresponding to the tail (lizards only; see text).

gle, 2018]. For all the analyses we show the magnitude of phylogenetic signal based on Pagel's $\lambda$ [Pagel, 1999], which estimates the extent to which correlations in traits reflect their shared evolutionary history (as approximated by Brownian motion).

To estimate the potential bias that reptile tails may introduce in comparisons of relative brain size, we obtained data from the literature on the size of the tail in several lizard species (online suppl. Table ESM2). We then recalculated the brain volume-body volume PGLS regressions for birds and reptiles using body volume values for lizards excluding the tail (volume minus tail). Lizard tail volumes were calculated using family-specific relative tail sizes (i.e., the unweighted average of the available data for species within that family; for lacertid lizards we excluded two Takydromus species as this genus exhibits extraordinarily elongate tails). For those families for which we could not get information on tail size we used a relative tail size of 0.22 (the average of all the available data for lizards). We ran a similar analysis to estimate the effect of the turtle shell in relative brain size calculations. In this case, we collected data from the literature on the proportion of body mass accounted for by the carapace and plastron (online suppl. Table ESM3), then recalculated the brain volume-body volume regression for reptiles using turtle body volume estimates that did not take these dense structures into account. Corrected turtle body volumes were calculated using a relative shell weight of 0.32 (the unweighted average of all the available data). Note that we did not correct body volume for Apalone ferox, the only species of turtle in our dataset with a soft shell.

\section{Results}

Our expanded dataset comprises brain and body mass data for 175 species of reptiles, which almost doubles the sample size of previous studies (dataset available from the Dryad Digital Repository: DOI: 10.5061/dryad.pd5hh46).
Lizards make up $84 \%$ of the sample, while snakes ( 15 species), turtles (9 species), and particularly crocodiles (2 species) are relatively underrepresented. Figure 2 shows scatterplots and best-fit phylogenetically corrected (PGLS) regression lines for mass and volume data. Among reptiles, the lowest relative brain weights are found in turtles and snakes (note that most of the points for these two groups fall below the regression line in Fig. 2a). However, correcting the data to account for the dense shell brings the data points for turtles closer to the allometric line (Fig. 2b).

Figure $3 \mathrm{a}$ shows the minimum convex polygons and phylogenetically corrected (PGLS) regression lines for reptiles and for a sample of 934 bird species. For all body sizes bird brains are heavier than reptile brains, but there is considerable variation within both groups. Absolute brain mass in reptiles ranges from $0.0045 \mathrm{~g}$ in the Australian skink Lerista muelleri to $15.6 \mathrm{~g}$ in the American crocodile, Crocodylus acutus. In birds, absolute brain size ranges from $0.167 \mathrm{~g}$ in the hummingbird Phaetornis ruber to $44.3 \mathrm{~g}$ in the Emperor penguin Aptenodytes forsteri.

Birds also have brains that are larger than those of reptiles relative to their body mass. The magnitude of the difference obviously depends on the species being compared. Thus, the brain of an $80-\mathrm{kg}$ ostrich weighs $41.9 \mathrm{~g}$, while that of a 134-kg crocodile weighs $15.6 \mathrm{~g}$ - i.e., less than a 3 -fold difference. The crocodile brain represents a mere $0.2 \%$ of its body mass; in contrast, the brain of a 0.5 $\mathrm{kg}$ macaw accounts for $2.5 \%$ of its body mass.

Table 1 shows the results of phylogenetically corrected (PGLS) regression analyses. Although results are similar 
Fig. 3. Polygon plots showing the distribution of relative brain size in birds (upper polygons; $n=934$ ) and non-avian reptiles (lower polygons; $n=175$ ). Phylogenetically corrected (PGLS) regression lines are shown. Note that the polygons for birds and reptiles are closer to each other using volume (b) rather than mass (a). The separation of the intercepts of the regression lines corresponds to a 6.5 -fold difference in brain mass and a 5.4-fold difference in volume between birds and reptiles. a Brain mass was measured in milligrams and body mass in grams. b Brain volume was measured in microliters and body volume in milliliters.
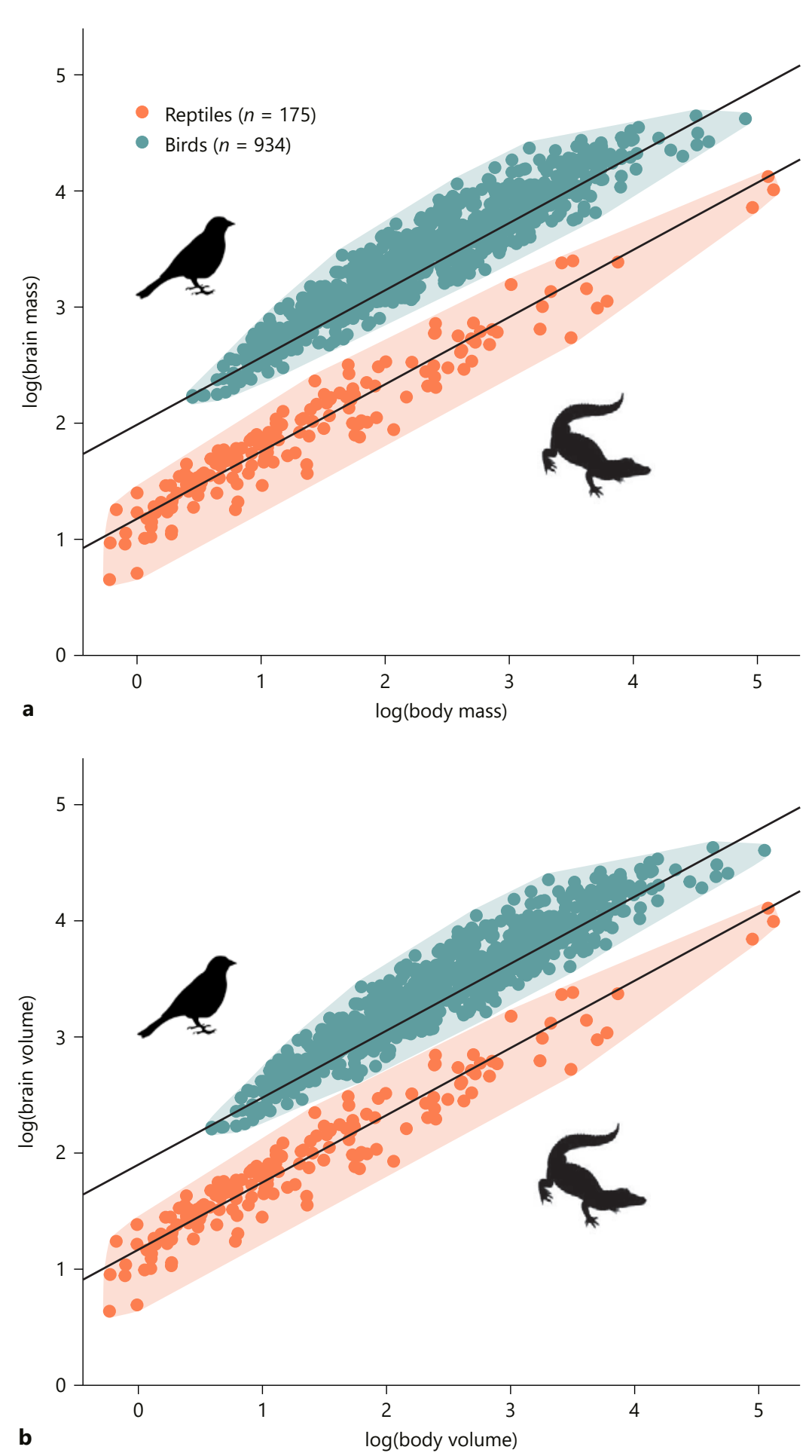
regardless of whether species are treated as independent data points (data not shown) or if phylogeny is taken into account, the presence of a strong phylogenetic signal $(\lambda>$ 0.8 ) indicates that non-phylogenetic analyses are inappropriate to compare bird and reptile relative brain size.

Phylogenetic tests returned strongly consistent results for differences between slopes and intercepts. First, tests of the relationship between brain mass variation as a scaling function of body mass revealed significant differences between birds and reptiles in intercepts holding slopes constant $(n=735, \lambda=0.527, t=4.46, p<0.0001)$, while no significant differences were found when comparing slopes holding intercepts constant $(n=735, \lambda=0.526, t=0.129$, $p=0.897$ ). A subsequent test based on a model that holds slopes constant against a model in which both intercepts and slopes vary confirmed that no differences exist between slopes $\left(F_{2,731}=1.12, p=0.29\right)$. The same analyses performed on brain volume and body volume showed significant differences in intercepts holding slopes constant ( $n=735, \lambda=0.518, t=4.02, p<0.0001$ ), while tests of slopes holding intercepts constant showed no significant differences between birds and reptiles $(n=735, \lambda=0.516$, $t=0.209, p=0.834$ ). The test of the model that holds slopes constant against a model in which both intercepts and slopes vary confirmed that no differences exist between slopes $\left(F_{2,731}=1.32, p=0.25\right)$. Finally, the same analyses performed on brain and body volume were replicated, but after the effect of lizard tails was removed. Consistent with the above results, these analyses showed significant differences between intercepts holding slopes constant $(n=735$, $\lambda=0.571, t=3.39, p<0.001$ ), while no differences in slopes holding the intercept constant were observed between both clades $(n=735, \lambda=0.567, t=0.439, p=0.661)$. This finding was confirmed by a test of the model that holds slopes constant against a model in which both intercepts and slopes vary $\left(F_{2,731}=3.74, p=0.054\right)$.

The difference in relative brain mass between birds and reptiles, estimated from the separation between the intercepts of the corresponding PGLS regression lines, is 6.5fold $\left(\operatorname{antilog}_{10}(1.987-1.177)=\operatorname{antilog}_{10} 0.81=6.46\right)$. Substituting brain-body volume for brain-body mass yields similar results but the gap separating birds from reptiles all but disappears. Figure $3 \mathrm{~b}$ shows the polygons for birds and reptiles using brain and body volume data. Using volume rather than mass, the two polygons abut each other, and the average difference in brain size between birds and reptiles shrinks to 5.4-fold. Recalculating the brain volume-body volume regressions to exclude, for lizards only, the fraction of body volume corresponding to the tail, further reduces the gap between reptiles and birds to 4.8 .

Relative Brain Size in Reptilia

\section{Discussion}

Our large-scale comparative study provides a case study that highlights a range of potential sources of bias in the interpretation of relative brain size, all stemming from ignoring selection pressures that affect body size, the denominator in most estimates of relative brain size.

\section{Filling the Gap in the Evolution of Vertebrate Brain}

Size

Comparative studies have revealed considerable variation in relative brain size within and across vertebrate radiations [Northcutt, 2002; Striedter, 2005]. Birds and mammals have brains that are, all things considered, indisputably larger relative to their body size than those of reptiles, but the difference has traditionally been overestimated. As a result, the reptilian brain is often stereotyped as small, primitive, and consequently incapable of supporting complex behavior and cognition. This characterization is incorrect and based on outdated evidence [see also Northcutt, 2013].

All the early studies of brain size evolution, including Jerison's [1973], were affected by conclusions being drawn based on small sample sizes. Jerison [1973] used brain and body size data for a mere 20 species of reptiles. Subsequent studies have increased the coverage by adding more species from all four reptilian orders (62 species in Hurlburt [1996]; 74 species in van Dongen [1998]), but the basic conclusion regarding overall differences in brain size across vertebrate groups has remained unchanged and the 10-fold figure continues to be authoritatively quoted to describe the gap between birds and reptiles. Here we show that alternative analyses lead to different conclusions. Using an extended dataset and modern phylogenetic comparative methods that allow for a more accurate examination of relative brain size in reptiles we show that the actual value is 6.5 -fold. Substituting the often cited 10 -fold brain size difference for a more realistic 6.5 -fold difference may seem a modest change, but worth stressing considering that the literature on comparative neurobiology and cognition misrepresents reptiles by describing the divergence between reptiles and birds as more dichotomous and functionally important in stereotype-consistent ways than is warranted.

Accurate estimates of the allometric equation describing the relationship between brain and body size in living reptiles is important because it is often used to predict levels of encephalization in extinct reptiles such as pterosaurs and dinosaurs [Witmer et al., 2003; Hurlburt et al., 2013]. Our results show that the slope of the phylogenet-

Brain Behav Evol 2019;93:182-195 189 
Fig. 4. Polygon plots showing the distribution of relative brain size in four orders of birds using: brain and body mass (a), and brain and body volume (b; body volume calculated using specific gravity data for each of the four different orders; see online suppl. Table ESM1). The overlay polygon encloses the data points for all the birds in our dataset. The regression lines are from analyses of all the bird data. Note that correcting for their unusually high body density brings the data points for Suliformes further above the allometric line, suggesting they have brains that are relatively large for their body size. a Brain mass was measured in milligrams and body mass in grams. b Brain volume was measured in microliters and body volume in milliliters.

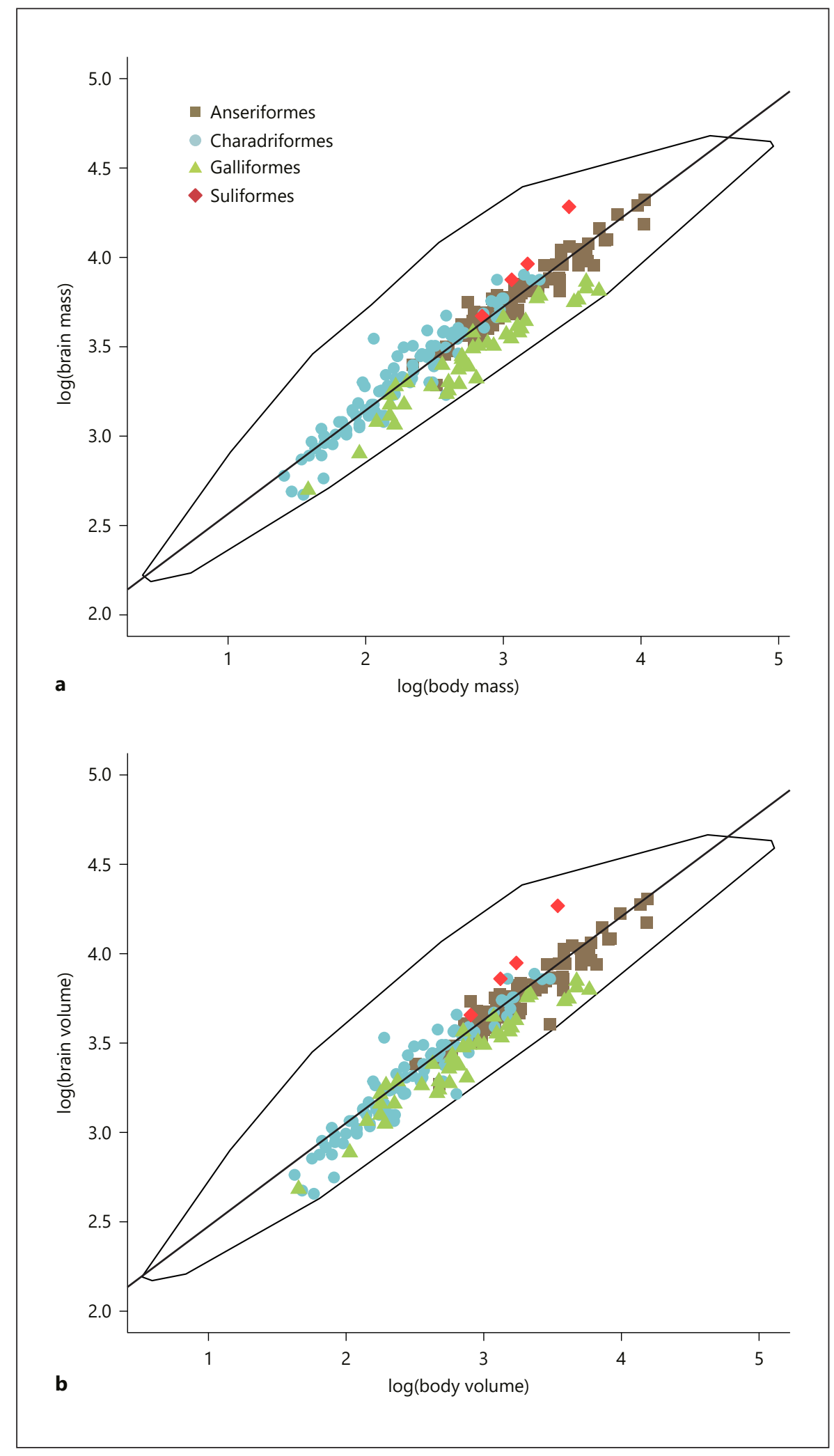




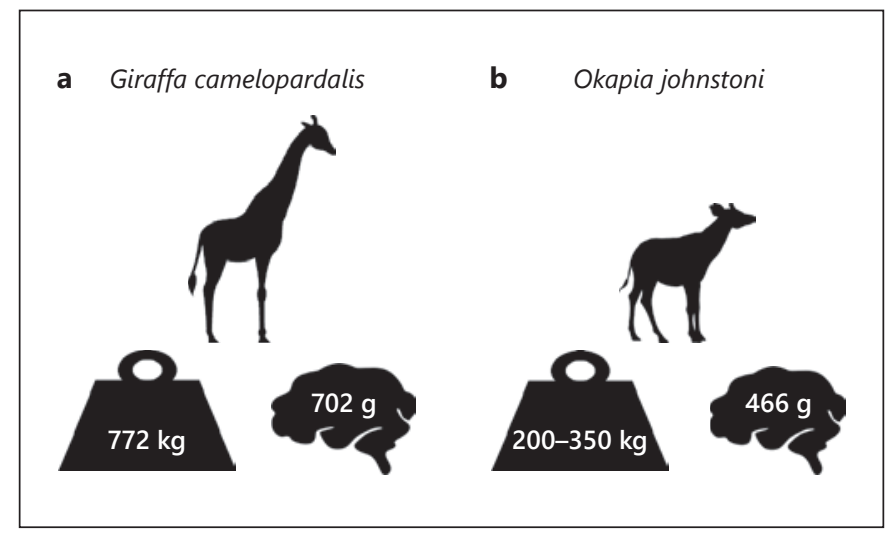

Fig. 5. Comparison of brain and body sizes in giraffes (G. camelopardalis) and the only other member of the Giraffidae, the okapi (O. johnstoni). Relative brain size in giraffes is considered extraordinarily small for a mammal. The average relative brain mass for the few specimens for which brain and body size data are available is $0.097 \%$ of body mass, with a maximum recorded estimate of 0.13\% [Black, 1915; Crile and Quiring, 1940; Graïc et al., 2017]. Brain size data for the short-necked okapi are mostly missing, with a single estimate of $466 \mathrm{~g}$ [Black, 1915]. Given that adult body size in okapi ranges from 200 to $350 \mathrm{~kg}$, this would yield a relative brain mass of $0.13-0.23 \%$, considerably larger than for their long-necked closest relatives.

ically corrected regression line relating brain and body mass in reptiles (0.579) is far from the $0.67(2 / 3)$ slope proposed by Jerison [1973] on theoretical grounds, but is similar to the slopes of $0.56,0.55$, and 0.53 reported by Martin [1981], Hurlburt [1996], and van Dongen [1998], respectively. That the slopes for birds and reptiles are not significantly different in any of the comparisons (mass, volume, and volume minus tail) refutes the notion that bird brains are capable of tracking increases in body size more accurately than reptile brains, resulting in a higher brain mass-body mass slope [Roth, 2013].

Our analyses reveal and quantify several sources of bias in the assessment of relative reptile brain size. In particular, the use of overall body mass as a scaling variable in comparisons between birds and reptiles is questionable given the strong directional selection towards reduced body mass in birds [Gill, 2007]. Our results show that using brain volume and body volume instead of mass brings the polygons for birds and reptiles even closer, reducing the average difference in relative brain size to 5.4-fold (compare Fig. 3a, b). Further reductions can be obtained by correcting for constraints imposed by the different bauplan of reptiles and birds (tails in crocodiles and lizards, dense shells in turtles), highlighting the need to take into account differences arising from selection pressures affecting body design. For example, van Dongen [1998] attributed the comparatively small brains of turtles to them being "primitive," rather than to the obvious fact that the shell increases the mass of turtles beyond what one would expect for a reptile of their body size. In fact, softshell turtles with their leathery shell - presumably much lighter than the shell of other turtles - are the only Chelonians in our dataset with a brain mass higher than expected for their body mass, and an outlier among the turtles unless a correction is made to account for the shell of other species (Fig. 2). Taking the above considerations into account, the traditional chasm in relative brain size between birds and non-avian reptiles shrinks considerably, which altogether paints a much more coherent and parsimonious picture of the evolution of brain size within Reptilia.

Interspecific variation in the selection pressures affecting body size, such as those relative to body density or bauplan, are not limited to comparisons between birds and reptiles, but generally applicable across all vertebrates [Smaers et al., 2012] and invertebrates [Wehner et al., 2007; Polilov and Makarova, 2017]. For example, cormorants (order Suliformes) are excellent divers, reaching depths of more than $40 \mathrm{~m}$ thanks, among other adaptations, to a particularly low buoyancy (i.e., high density) for a bird [Ribak et al., 2004]. Relative brain mass places Suliformes close to the regression line which suggests they have brains of the expected size for their body mass (Fig. 4a), but taking volume (and hence buoyancy) into account reveals that they actually have larger brains than expected (Fig. 4b). Galliformes, which also have dense bodies (see EMS1), have relatively small brains in a comparison based on mass (i.e., most points fall below the regression line), but their brains are closer to the expected size considering volume (Fig. 4). Similar arguments can be made for other orders of birds, and surely for many species of mammals. Giraffes, with their incredibly long necks, are an excellent example of how differences in bauplan can affect estimates of relative brain size. Giraffidae have only two extant species, the long-necked giraffe ( $G i$ raffa camelopardalis) and the short-necked okapi (Okapia johnstoni). While the giraffe is often described as a mammal with extraordinarily low relative brain size [Graïc et al., 2017; Raghanti et al., 2017], the short-necked okapi harbors a brain that is, unsurprisingly, about the expected size for an Artiodactyl of its body size. However, the difference between giraffe and okapi is not so much in the brain (their brains have roughly the same absolute mass; Fig. 5) as it is in the long and heavy neck, which makes up a large proportion of a giraffe's body mass [Simmons and Scheepers, 1996]. 
Recommendations for Future Studies of Relative Brain Size

We argue that future studies should not interpret differences across species or larger groups exclusively in terms of selection pressures acting on the brain but also look for differences in body density and bauplan that could potentially distort comparisons based on relative brain size. Comparative studies of brain evolution should be alert to peculiarities of the taxa under study, such as the possession of extremely long tails or large fat deposits, which may introduce systematic biases in calculations of body size. Although large, heavy bodies usually harbor large brains, the relationship between brain and body size is rather noisy (Fig. 1). A consideration of the bauplan of the species involved is necessary in order to disentangle phylogenetic and other sources of variation. Most snakes and legless lizards (e.g., Anguidae), for example, have small brain weights for their body weight (Fig. 2). However, this is likely the result of selection for a highly elongate body form rather than selection for small brains [van Dongen, 1998].

\section{From Relative Brain Size to Cognition: A Cautionary \\ Note}

Variation in brain size has been notoriously difficult to interpret [Healy and Harvey, 1990; Healy and Rowe, 2007; Chittka and Niven, 2009], and the link between brain size and cognition remains one of the thorniest issues in comparative neurobiology. However, many still consider that relative brain size is a robust proxy for general cognitive ability [Pollen et al., 2007; Burkart et al., 2017; Fristoe et al., 2017; Iwaniuk, 2017]. In accordance with this hypothesis, the much cited 10-fold difference in brain size has often been used to justify the cognitive superiority of birds relative to reptiles. Birds, with their relatively large brains, are currently considered on a par with mammals as far as their behavioral and cognitive complexity [Emery and Clayton, 2004]. In contrast, reptiles are widely considered, despite abundant evidence to the contrary, cognitive underachievers. Rather than questioning the rationale behind this conclusion, many authors have uncritically assumed that their small brains must condemn reptiles to a life of cognitive mediocrity. Snakes have been described as incapable of integrating information from different sensory modalities [Sjölander, 1995; Gärdenfors, 2003], crocodiles as devoid of any emotion [MacLean, 1985], and turtles as just plain stupid [Robin, 1973]. The unfortunate consequence of this misperception is that the cognitive abilities of reptiles are rarely tested. This, in turn, reinforces the notion that sophisticated cognition is all but absent in this group. In a recent review, Güntürkün and
Bugnyar [2016, p. 292] concluded that "although reptilian cognition should not be underestimated, nothing at the level and scope of bird cognition has been reported for this animal group so far." This is typical of much current thinking in comparative cognition. However, the persistent myth of the sluggish, primitive, stupid reptile is increasingly out of pace with reports describing examples of complex behavior and sophisticated cognition in many species of reptiles [Wilkinson and Huber, 2012; Burghardt, 2013; Doody et al., 2013]. That the brains of reptiles are not as large as those of birds and mammals makes their study even more interesting and brings about the challenge to explain how the relatively small brains of reptiles are capable of supporting their sophisticated behavior and cognition, not the other way around.

Still, speculations regarding cognitive abilities based solely on comparative brain size data are bound to lead us astray. Invertebrates, with their miniaturized brains, are a case in point. Many insects show remarkably sophisticated behavior and cognition, yet their brains are staggeringly small compared to those of vertebrates [Chittka and Niven, 2009]. Although the argument has been used mainly in the context of vertebrate-invertebrate comparisons, it should equally apply to comparisons among vertebrate groups: cognitive achievements do not strictly depend on the possession of relatively large brains. A large brain is thought to confer more intelligence because more brain tissue increases the computational capacity supporting behavioral and cognitive complexity. However, in vertebrates the correlation between brain size and cognitive ability is weak both intraspecifically and interspecifically [Healy and Rowe, 2007; Herculano-Houzel et al., 2014]. Furthermore, recent work by Olkowicz et al. [2016] has shown that birds have roughly twice as many neurons in their forebrain as mammals of similar brain mass. In fact, their study challenges deeply ingrained notions about the supposed cognitive superiority of primates, which to date largely relied on data on relative brain size. For example, a raven has the same number of neurons in the pallium of its 10 -g brain as a capuchin monkey in the cortex of its 39-g brain, and a blue-and-yellow macaw packs more neurons in the pallium of its 14 -g brain than a macaque monkey in the cortex of its 70-g brain [Olkowicz et al., 2016]. This suggests that the packing density of neurons in some telencephalic areas, rather than brain size, may explain the sophisticated cognition found in some birds such as parrots and corvids. Unfortunately, the same analysis has not been conducted with reptiles or other vertebrates, such as fish, which are equally capable of sophisticated behavior and cognition [Brown et al., 2011]. 


\section{Acknowledgements}

We thank the following colleagues for generously sharing with us their unpublished data on lizard brain size: Brian J. Powell and Manuel Leal (Anolis spp.), Lauren M. Davis and Michele A. Johnson (Coleonyx brevis, Hemidactylus turcicus), and Daniel Robert Pfau and Christy Strand (Sceloporus occidentalis). The helpful comments of G. Striedter and two anonymous reviewers are greatly appreciated. Matt Kramer helped with the logarithms.

\section{Statement of Ethics}

The authors have no ethical conflicts to disclose. No experiments on living animals were performed, and no animal was euthanized purposefully for the work reported here.

\section{Disclosure Statement}

The authors declare no conflicts of interest.

\section{References}

Amiel JJ, Tingley R, Shine R. Smart moves: effects of relative brain size on establishment success of invasive amphibians and reptiles. PLoS One. 2011 Apr;6(4):e18277.

Armstrong E, Bergeron R. Relative brain size and metabolism in birds. Brain Behav Evol. 1985; 26(3-4):141-53.

Black DG. Encephalization of Australian lizards [thesis]. Melbourne: Monash University; 1983.

Brown C, Laland K, Krause J. Fish cognition and behavior. Oxford: Wiley-Blackwell; 2011. https://doi.org/10.1002/9781444342536.

Burghardt GM. Environmental enrichment and cognitive complexity in reptiles and amphibians: Concepts, review, and implications for captive populations. Appl Anim Behav Sci. 2013; 147(3-4):286-98.

Burkart JM, Schubiger MN, van Schaik CP. The evolution of general intelligence. Behav Brain Sci. 2017 Jan;40:e195.

Burleigh JG, Kimball RT, Braun EL. Building the avian tree of life using a large-scale, sparse supermatrix. Mol Phylogenet Evol. 2015 Mar; 84:53-63.

Butler $\mathrm{AB}$, Hodos W. Comparative Vertebrate Neuroanatomy: Evolution and Adaptation. 2nd ed. Hoboken (New Jersey): John Wiley and Sons; 2005. https://doi.org/10.1002/ 0471733849.

Chittka L, Niven J. Are bigger brains better? Curr Biol. 2009 Nov;19(21):R995-1008.

Cnotka J, Güntürkün O, Rehkämper G, Gray RD, Hunt GR. Extraordinary large brains in toolusing New Caledonian crows (Corvus moneduloides). Neurosci Lett. 2008 Mar;433(3): 241-5.

Colbert EH. The weights of dinosaurs. Am Mus Novit. 1962;2076:1-16.

Corfield JR, Birkhead TR, Spottiswoode CN, Iwaniuk AN, Boogert NJ, Gutiérrez-Ibáñez C, et al. Brain size and morphology of the broodparasitic and cerophagous honeyguides (Aves: piciformes). Brain Behav Evol. 2013; 81(3): 170-86.

Crile G, Quiring DP. A record of the body weight and certain organ and gland weights of 3,690 animals. Ohio J Sci. 1940;40:219-59.

Day LB, Westcott DA, Olster DH. Evolution of bower complexity and cerebellum size in bowerbirds. Brain Behav Evol. 2005;66(1): 62-72.
Deacon TW. Rethinking mammalian brain evolution. Am Zool. 1990;30(3):629-705.

Dicke U, Roth G. Neuronal factors determining high intelligence. Philos Trans R Soc Lond B Biol Sci. 2016 Jan;371(1685):20150180.

Domínguez Alonso P, Milner AC, Ketcham RA, Cookson MJ, Rowe TB. The avian nature of the brain and inner ear of Archaeopteryx. Nature. 2004 Aug;430(7000):666-9.

Doody JS, Burghardt GM, Dinets V. Breaking the social-non-social dichotomy: a role for reptiles in vertebrate social behavior research? Ethology. 2013;119(2):95.

Emery NJ, Clayton NS. Comparing the complex cognition of birds and primates. In: Rogers LJ, Kaplan G, editors. Comparative Vertebrate Cognition. Dordrecht: Kluwer Academic/ Plenum; 2004. pp. 3-55.

Emery NJ, Clayton NS, Frith CD. Social Intelligence: From Brain to Culture. Oxford: Oxford University Press; 2007.

Fristoe TS, Iwaniuk AN, Botero CA. Big brains stabilize populations and facilitate colonization of variable habitats in birds. Nat Ecol Evol. 2017 Nov;1(11):1706-15.

Galván I, Møller AP. Brain size and the expression of pheomelanin-based colour in birds. J Evol Biol. 2011 May;24(5):999-1006.

Garamszegi LZ, Møller AP, Erritzøe J. Coevolving avian eye size and brain size in relation to prey capture and nocturnality. Proc Biol Sci. 2002 May;269(1494):961-7.

Gärdenfors P. How Homo Became Sapiens: On the Evolution of Thinking. Oxford: Oxford University Press; 2003.

Gill F. Ornithology. 3rd ed. New York: W.H. Freeman; 2007.

Graï JM, Peruffo A, Ballarin C, Cozzi B. The brain of the giraffe (Giraffa camelopardalis): surface configuration, encephalization quotient, and analysis of the existing literature. Anat Rec (Hoboken). 2017 Aug;300(8):1502-11.

Güntürkün $\mathrm{O}$, Bugnyar T. Cognition without Cortex. Trends Cogn Sci. 2016 Apr;20(4): 291-303.

Güntürkün O, Stacho M, Ströckens F. The brains of reptiles and birds. In: Kaas J, editor. Evolution of Nervous Systems. Volume 1. 2nd ed. Oxford: Elsevier; 2017. pp. 171-221.
Hamershock DM, Seamans TW, Bernhardt GE. Determination of body density for twelve bird species. Ibis. 1993; 137:424-8.

Hansen TF, Bartoszek K. Interpreting the evolutionary regression: the interplay between observational and biological errors in phylogenetic comparative studies. Syst Biol. 2012 May;61(3):413-25.

Harmon LJ, Weir JT, Brock CD, Glor RE, Challenger W. GEIGER: investigating evolutionary radiations. Bioinformatics. 2008 Jan; 24(1):129-31.

Harvey PH, Pagel MD. The allometric approach to species differences in brain size. Hum Evol. 1988;3(6):461-72.

Hazlehurst GA. The morphometric and flight characteristics of the Pterosauria [thesis]. Bristol: University of Bristol; 1991.

Hazlehurst GA, Rayner JM. Flight characteristics of Triassic and Jurassic Pterosauria: an appraisal based on wing shape. Paleobiology. 1992;18(4):447-63.

Healy SD, Harvey PH. Comparative studies of the brain and its components. Neth J Zool. 1990; 40:203-14

Healy SD, Rowe C. A critique of comparative studies of brain size. Proc Biol Sci. 2007 Feb; 274(1609):453-64.

Hedges SB, Dudley J, Kumar S. TimeTree: a public knowledge-base of divergence times among organisms. Bioinformatics. 2006 Dec; 22(23):2971-2.

Herculano-Houzel S, Manger PR, Kaas JH. Brain scaling in mammalian evolution as a consequence of concerted and mosaic changes in numbers of neurons and average neuronal cell size. Front Neuroanat. 2014 Aug;8:77.

Hochscheid S, Bentivegna F, Speakman JR. The dual function of the lung in chelonian sea turtles: buoyancy control and oxygen storage. J Exp Mar Biol Ecol. 2003;297(2):123-40.

Hurlburt G. Comparison of body mass estimation techniques, using recent reptiles and the pelycosaur Edaphosaurus boanerges. J Vertebr Paleontol. 1999;19(2):338-50.

Hurlburt GR. Relative brain size in recent and fossil amniotes: determination and interpretation [thesis]. Toronto: University of Toronto; 1996. 
Hurlburt GR, Ridgely RC, Witmer LM. Relative size of brain and cerebrum in Tyrannosasurus rex: an analysis using brain-endocast quantitative relationships in extant alligators. In: Parrish JM, Henderson M, Currie PJ, Koppelhus E, editors. Origin, Systematics, and Paleobiology of the Tyrannosauridae. DeKalb: Northern Illinois University Press; 2013. pp. 134-54.

Iwaniuk AN. The evolution of cognitive brains in non-mammals. In: Watanabe S, Hofman MA, Shimizu T, editors. Evolution of the brain, cognition, and emotion in vertebrates. Berlin: Springer; 2017. pp. 101-24.

Iwaniuk AN, Arnold KE. Is cooperative breeding associated with bigger brains? A comparative test in the Corvida (Passeriformes). Ethology. 2004;110(3):203-20.

Iwaniuk AN, Nelson JE. A comparative analysis of relative brain size in waterfowl (Anseriformes). Brain Behav Evol. 2001 Feb;57(2): 87-97.

Iwaniuk AN, Nelson JE. Can endocranial volume be used as an estimate of brain size in birds? Can J Zool. 2002;80(1):16-23.

Jackson DC. Buoyancy control in the freshwater turtle, Pseudemys scripta elegans. Science. 1969 Dec;166(3913):1649-51.

Jagnandan K, Russell AP, Higham TE. Tail autotomy and subsequent regeneration alter the mechanics of locomotion in lizards. J Exp Biol. 2014 Nov;217(Pt 21):3891-7.

Jarvis ED. Evolution of the pallium in birds and reptiles. In: Binder MD, Hirokawa N, Windhorst U, editors. New Encyclopedia of Neuroscience. Berlin: Springer-Verlag; 2009. pp. 1390-400.

Jerison HJ. Evolution of the Brain and Intelligence. New York: Academic Press; 1973.

MacLean PD. Brain evolution relating to family, play, and the separation call. Arch Gen Psychiatry. 1985 Apr;42(4):405-17.

Martin RD. Relative brain size and basal metabolic rate in terrestrial vertebrates. Nature. 1981 Sep;293(5827):57-60.

Menzel R, Fischer J. Animal thinking: An introduction. In: Menzel R, Fisher J, editors. Animal Thinking: Contemporary Issues in Comparative Cognition. Cambridge (Massachusetts): MIT Press; 2011. pp. 1-6.

Mlikovsky J. Brain size in birds: 1. Tinamiformes through Ciconiiformes. Vest Cesk Spolec Zool. 1989a;53:33-47.

Mlikovsky J. Brain size in birds: 2. Falconiformes through Gaviiformes. Vest Cesk Spolec Zool. 1989b;53:200-213.

Mlikovsky J. Brain size in birds: 3. Columbiformes through Piciformes. Vest Cesk Spolec Zool. 1989c;53:252-264.

Mlikovsky J. Brain size in birds: 4. Passeriformes. Acta Soc Zool Bohemoslov. 1989d;54:27-37.

Montgomery SH, Mundy NI, Barton RA. Brain evolution and development: adaptation, allometry and constraint. Proc Biol Sci. 2016 Sep;283(1838):20160433.
Northcutt RG. Understanding vertebrate brain evolution. Integr Comp Biol. 2002 Aug;42(4): 743-56.

Northcutt RG. Paleontology. Evolving large and complex brains. Science. 2011 May;332(6032): 926-7.

Northcutt RG. Variation in reptilian brains and cognition. Brain Behav Evol. 2013;82(1):4554.

Olkowicz S, Kocourek M, Lučan RK, Porteš M, Fitch WT, Herculano-Houzel S, et al. Birds have primate-like numbers of neurons in the forebrain. Proc Natl Acad Sci USA. 2016 Jun; 113(26):7255-60.

Orme CDL, Freckleton RP, Thomas GH, Petzoldt T, Fritz SA, Isaac NJB. CAPER: Comparative Analyses of Phylogenetics and Evolution in R. 2012.

Padian K, Chiappe LM. The origin and early evolution of birds. Biol Rev Camb Philos Soc. 1998; 73(1):1-42.

Pagel M. Inferring the historical patterns of biological evolution. Nature. 1999 Oct;401(6756): 877-84.

Pagel MD, Harvey PH. The taxon-level problem in the evolution of mammalian brain size: facts and artifacts. Am Nat. 1988;132(3):34459.

Paradis E, Claude J, Strimmer K. APE: analyses of phylogenetics and evolution in $\mathrm{R}$ language. Bioinformatics. 2004 Jan;20(2):289-90.

Payne RB. The Cuckoos. Oxford: Oxford Univ. Press; 2005.

Peterson CC, Gomez D. Buoyancy regulation in two species of freshwater turtle. Herpetologica. 2008;64(2):141-8.

Pinheiro J, Bates D, DebRoy S, Sarkar D. nlme: linear and nonlinear mixed effects models. $\mathrm{R}$ package version 3.1-137. R Core Team; 2018.

Platel R. Poids encéphalique et indice d'encéphalisation chez les reptiles sauriens. Zool Anz. 1974;192:332-82.

Platel R. Nouvelles données sur l'encéphalisation des reptiles squamates. Z Zool Syst Evol. 1975; 13:161-184

Platel R. Brain weight-body weight relationships. In: Gans CG, Northcutt RG, Ulinski PS, editors. Biology of the Reptilia. Volume 10. London: Academic Press; 1979. pp. 147-71.

Polilov AA, Makarova AA. The scaling and allometry of organ size associated with miniaturization in insects: A case study for Coleoptera and Hymenoptera. Sci Rep. 2017 Feb; 7(1):43095.

Pollen AA, Dobberfuhl AP, Scace J, Igulu MM, Renn SC, Shumway CA, et al. Environmental complexity and social organization sculpt the brain in Lake Tanganyikan cichlid fish. Brain Behav Evol. 2007;70(1):21-39.

$\mathrm{R}$ Core Team. R: a language and environment for statistical computing. Vienna: R Foundation for Statistical Computing; 2014. http:// www.r-project.org/.
Raghanti MA, Munger EL, Wicinski B, Butti C, Hof PR. Comparative structure of the cerebral cortex in large mammals. In: HerculanoHouzel S, editor. Evolution of Nervous Systems: The Nervous System of Early Mammals and their Evolution. Volume 2. Amsterdam: Elsevier; 2017. pp. 267-89.

Rehkämper G, Schuchmann KL, Schleicher A Zilles K. Encephalization in hummingbirds (Trochilidae). Brain Behav Evol. 1991;37(2): 85-91.

Revell LJ. phytools: an R package for phylogenetic comparative biology (and other things). Methods Ecol Evol. 2012;3(2):217-23.

Ribak G, Weihs D, Arad Z. How do cormorants counter buoyancy during submerged swimming? J Exp Biol. 2004 May;207(Pt 12):210114.

Robin ED. The evolutionary advantages of being stupid. Perspect Biol Med. 1973;16(3):36980.

Roquet C, Lavergne S, Thuiller W. One tree to link them all: a phylogenetic dataset for the European tetrapoda. PLOS Curr. 2014;1. https:// doi.org/10.1371/currents.tol.5102670fff8aa5c 918e78f5592790e48.

Roth G. The Long Evolution of Brains and Minds. Dordrecht: Springer; 2013. https://doi org/10.1007/978-94-007-6259-6.

Schmidt-Nielsen K. Scaling: Why is Animal Size So Important? Cambridge: Cambridge University Press; 1984. https://doi.org/10.1017/ CBO9781139167826.

Shettleworth SJ. Cognition, Evolution, and Behavior. 2nd ed. Oxford: Oxford University Press; 2010.

Shimizu T, Shinozuka K, Uysal AK, Leilani Kel$\operatorname{logg} \mathrm{S}$. The origins of the bird brain: multiple pulses of cerebral expansion in evolution; in Watanabe S, Hofman MA, Shimizu T, editors. Evolution of the brain, cognition, and emotion in vertebrates. Berlin: Springer; 2017. pp. $35-57$.

Simmons RE, Scheepers L. Winning by a neck: sexual selection in the evolution of giraffe. Am Nat. 1996;148(5):771-86.

Sjölander S. Some cognitive breakthroughs in the evolution of cognition and consciousness, and their impact on the biology of language. Evol Cogn. 1995;1:3-11.

Smaers JB, Dechmann DK, Goswami A, Soligo C Safi K. Comparative analyses of evolutionary rates reveal different pathways to encephalization in bats, carnivorans, and primates. Proc Natl Acad Sci USA. 2012 Oct;109(44): 18006-11.

Smaers JB, Mongle CS. Evomap: $r$ package for the evolutionary mapping of continuous traits. Github; 2018. https://github.com/JeroenSmaers/evomap.

Smaers JB, Rohlf FJ. Testing species' deviation from allometric predictions using the phylogenetic regression. Evolution. 2016 May; 70(5):1145-9.

Smith RJ. Use and misuse of the reduced major axis for line-fitting. Am J Phys Anthropol. 2009 Nov;140(3):476-86. 
Sokal RR, Rohlf FJ. Biometry: The Principles and Practice of Statistics in Biological Research. New York: Freeman; 2012.

Striedter GF. Principles of Brain Evolution. Sunderland: Sinauer Associates; 2005.

Symonds MR, Blomberg SP. A primer on phylogenetic generalised least squares (PGLS). In: Garamszegi LZ, editor. Modern Phylogenetic Comparative Methods and Their Application in Evolutionary Biology: Concepts and Practice. Berlin: Springer; 2014. pp. 105-30.

Tonini JF, Beard KH, Ferreira RB, Jetz W, Pyron RA. Fully-sampled phylogenies of squamates reveal evolutionary patterns in threat status. Biol Conserv. 2016;204:23-31.

Tosches MA, Yamawaki TM, Naumann RK, Jacobi AA, Tushev G, Laurent G. Evolution of pallium, hippocampus, and cortical cell types revealed by single-cell transcriptomics in reptiles. Science. 2018 May;360(6391):881-8. van Dongen PA. Brain size in vertebrates. In: Nieuwenhuys R, ten Donkelaar HJ, Nicholson C, editors. The Central Nervous System of Vertebrates. Volume 3. Berlin: Springer-Verlag; 1998. pp. 2099-134.

Warton DI, Wright IJ, Falster DS, Westoby M. Bivariate line-fitting methods for allometry. Biol Rev Camb Philos Soc. 2006 May;81(2): 259-91.

Wedel MJ. Postcranial skeletal pneumaticity in sauropods and its implications for mass estimates. In: Curry-Rogers KA, Wilson JA, editors. The Sauropods: Evolution and Paleobiology. Berkeley (CA): University of California Press; 2005. pp. 201-28.
Wehner R, Fukushi T, Isler K. On being small: brain allometry in ants. Brain Behav Evol. 2007;69(3):220-8.

Wilkinson A, Huber L. Cold-blooded cognition: Reptilian cognitive abilities. In: Vonk J, Shackelford TK, editors. The Oxford Handbook of Comparative Evolutionary Psychology. New Jersey: Oxford University Press; 2012. pp. 129-43.

Witmer LM, Chatterjee S, Franzosa J, Rowe T. Neuroanatomy of flying reptiles and implications for flight, posture and behaviour. $\mathrm{Na}$ ture. 2003 Oct;425(6961):950-3.

Yamashita W, Nomura T. The neocortex and dorsal ventricular ridge: functional convergence and underlying developmental mechanisms. In: Shigeno S, Murakami Y, Nomura T, editors. Brain evolution by design. Berlin: Springer; 2017. pp. 291-309. 